\title{
ANALYSIS OF CEREBRAL VENOUS THROMBOSIS IN PUERPERIUM
}

\author{
Sumathi Natarajan1, Mallika Selvaraj²
}

${ }_{1}^{1}$ Professor, Department of Obstetrics \& Gynaecology, Madurai Medical College.

${ }^{2}$ Assistant Professor, Department of Obstetrics \& Gynaecology, Madurai Medical College.

\section{ABSTRACT}

\section{AIM}

To study the incidence of CVT in Govt. Rajaji Hospital as well as the symptoms, cause, course, prognostic factors, morbidity and mortality in CVT and role of heparin in reducing morbidity.

\section{METHODOLOGY}

Retrospective study taken at Govt. Rajaji Hospital, Madurai Medical College, during the period of Feb 2014 to January 2015.

\section{RESULTS}

The study proved that incidence of CVT is significantly high in first two weeks of puerperium [p value 0.040] and is also more in patients delivered by labour naturalis $(68.7 \%)$ [p value 0.003 ].

\section{DISCUSSION}

As proved by our study the incidence of CVT is significantly higher in puerperal period and early diagnosis by MRI and heparin administration has an important role in reducing the mortality and morbidity associated with CVT.

\section{CONCLUSION}

MRI is the gold standard diagnostic tool for CVT. Heparin and corticosteroids are beneficial for recovery and in puerperal period anaemia, dehydration apart from hypercoagulable state increase the risk several fold.

\section{KEYWORDS}

CVT, Heparin, Puerperium, MRI, CT Scan.

HOW TO CITE THIS ARTICLE: Natarajan S, Selvaraj M. Analysis of cerebral venous thrombosis in puerperium. J. Evolution Med. Dent. Sci. 2016;5(52):3400-3404, DOI: 10.14260/jemds/2016/785

\section{INTRODUCTION}

Women in puerperal period can suffer from several neurological disorders, but a few of them can occur or deteriorate because of the physiological events in puerperal period. The classic example of such events occurring in puerperium is cerebral venous thrombosis. Puerperal CVT-an important cause for neurological disabilities, stroke and in worst case scenarios is also responsible for maternal death. Puerperal CVT is primary in contrast to secondary CVT seen both in men and women after brain injury, infections, metastatic and non-metastatic lesions. As discussed in our study, early diagnosis with CT scan and MRI with MRA/MRV and specific therapy with heparin and other supportive measures like steroids and mannitol mortality can be reduced and recovery is excellent.

\section{AIM OF THIS STUDY}

1. To find out the incidence of CVT in puerperium at GRH, Madurai.

2. The importance of early diagnosis and management.

3. To study the symptoms, causes, course, prognostic morbidity and mortality in CVT.

Financial or Other, Competing Interest: None.

Submission 12-05-2016, Peer Review 08-06-2016,

Acceptance 14-06-2016, Published 29-06-2016.

Corresponding Author:

Dr. Sumathi Natarajan,

Suba Clinic, \#2, Tagore Nagar,

Thiruppalai,

Madurai-625014.

E-mail: sumathibaskaran88@gmail.com

DOI: $10.14260 /$ jemds $/ 2016 / 785$

\section{MATERIALS AND METHODS}

Retrospective study was taken at Govt. Rajaji Hospital, Madurai Medical College, Madurai, during the period of Feb. 2014 to January 2015. Among the total number of obstetric admissions during this period of 12036 patients, 48 patients admitted with impairment of consciousness, seizures or focal neurological deficit were evaluated. History of patients with known epilepsy, post-partum eclampsia, CNS infections, head injury were excluded from study. Data regarding age, parity, time of occurrence, mode of delivery, various symptoms were taken. Blood investigation report such as renal function test, APLA were collected. MRI with MRA/MRV report available for the above patients. Neurophysician's opinion was obtained for all the patients and were treated with anticonvulsants, antioedema measures and anticoagulants and patients were followed up till their discharge. Treatment and recovery details collected.

\section{ANALYSIS}

The incidence at Govt. Rajaji Hospital, Madurai, was 3.9 per 1000 obstetric admissions.

\begin{tabular}{|c|c|c|}
\hline Population & No. of Cases & Percentage \\
\hline Rural & 36 & 75 \\
\hline Urban & 12 & 25 \\
\hline Total & $\mathbf{4 8}$ & $\mathbf{1 0 0}$ \\
\hline
\end{tabular}

36 out of 48 patients ( $75 \%$ ) belonged to rural population.

\begin{tabular}{|c|c|c|}
\hline Status & No. of Cases & Percentage \\
\hline Class III & 2 & 4.1 \\
\hline Class IV & 14 & 29.1 \\
\hline Class V & 32 & 66.6 \\
\hline \multicolumn{2}{|c|}{ Socio-Economic Status } \\
\hline
\end{tabular}


The important predisposing factor such as anaemia, which is more prevalent among class $\mathrm{V}$ socio-economic status contribute $66.6 \%$ of cases.

\begin{tabular}{|c|c|c|}
\hline Age in Years & No. of Cases & Percentage \\
\hline $16-20$ & 3 & 6.3 \\
\hline $21-30$ & 43 & 89.5 \\
\hline $31-35$ & 2 & 4.2 \\
\hline Total & $\mathbf{4 8}$ & $\mathbf{1 0 0}$ \\
\hline
\end{tabular}

43 out of 48 patients were in III decade, is significantly higher when compared to other decades. $\mathrm{P}$ value is significant $<0.001$.

\begin{tabular}{|c|c|c|c|}
\hline Parity & No. of Cases & Percentage & $\begin{array}{c}\text { Srinivasan Series } \\
\text { 135 Cases }\end{array}$ \\
\hline Primi & 20 & 42 & 22 \\
\hline Multi & 28 & 58 & 113 \\
\hline
\end{tabular}

CVT occurred in 28 multiparous women, which correlates with previous studies.

\begin{tabular}{|c|c|c|}
\hline Booking Status & No. of Cases & Percentage \\
\hline Unbooked & 2 & 4.2 \\
\hline Booked GRH & 12 & 25 \\
\hline Outside & 34 & 70.8 \\
\hline
\end{tabular}

Majority of cases 34 out of 48 patients (70\%) were booked outside, which implies mother with improper care are more affected.

\begin{tabular}{|c|c|c|}
\hline Post-Partum Period & No. of Cases & Percentage \\
\hline 3-14 days & 28 & 58.3 \\
\hline 15-28 days & 16 & 33.3 \\
\hline 28-42 days & 4 & 8.4 \\
\hline \multicolumn{2}{|c|}{ Time of Occurrence } \\
\hline
\end{tabular}

$58 \%$ of cases were seen in the first 2 weeks of puerperium $P$ value $=0.040$ significant.

Women belonging to low socio-economic status are not inclined to maintain adequate hydration in puerperium may be contributing.

\begin{tabular}{|c|c|c|}
\hline Place of Delivery & No. of Cases & Percentage \\
\hline Home delivery & 2 & 4.2 \\
\hline Private Hospital & 8 & 16.6 \\
\hline Govt. Rajaji Hospital & 12 & 25 \\
\hline Other Govt. Hospital \& PHC & 26 & 54.2 \\
\hline \multicolumn{2}{|c|}{ Place of Delivery } \\
\hline
\end{tabular}

CVT occurred in 12 patients delivered at GRH, Madurai. The lowest incidence with institutional delivery may be due to corrections of predisposing factors such as anaemia, avoidance of dehydration and maternal education.

\begin{tabular}{|c|c|c|}
\hline Mode of Delivery & No. of Cases & Percentage \\
\hline Labour natural & 33 & 68.7 \\
\hline Instrumental & 4 & 8.4 \\
\hline LSCS & 11 & 22.9 \\
\hline \multicolumn{2}{|c|}{ Mode of Delivery } \\
\hline
\end{tabular}

Maximum no. of cases $68.7 \%$ occurred following full-term normal delivery. Heparin prophylaxis in post-operative cases.
The incidence of thrombosis decreased in post-operative cases.

$P$ value $=0.003$ significant .

Inj. Heparin 5000 units subcutaneous was given as prophylaxis to patients following LSCS in post-operative period with high risk factors.

\begin{tabular}{|c|c|c|c|}
\hline $\begin{array}{c}\text { Clinical } \\
\text { Features }\end{array}$ & Number & $\begin{array}{c}\text { Present } \\
\text { Study }\end{array}$ & $\begin{array}{c}\text { Srinivasan } \\
\text { Series }\end{array}$ \\
\hline Coma & 6 & 12.5 & 45.2 \\
\hline Aphasia & 4 & 8.4 & 2.2 \\
\hline Blindness & 2 & 4.1 & 5.2 \\
\hline $\begin{array}{c}\text { Focal or } \\
\text { Generalised } \\
\text { Seizure }\end{array}$ & 44 & 91.6 & 28.7 \\
\hline Paresis & 13 & 27.1 & 47.4 \\
\hline Fever & 6 & 12.5 & 14.1 \\
\hline Hypertension & 5 & 10.4 & 5.2 \\
\hline Headache & 36 & 75 & 48.4 \\
\hline Vomiting & 29 & 60.4 & 24.2 \\
\hline Papilloedema & 3 & 6.2 & 15.5 \\
\hline Hypotension & 1 & 2.1 & 7.4 \\
\hline \multicolumn{2}{|c|}{ Clinical Profile } \\
\hline
\end{tabular}

These women are presenting in semi-stuporous condition with headache and focal or generalized convulsion followed with aphasia.

\begin{tabular}{|c|c|c|}
\hline Results & No. of Cases & Percentage \\
\hline Complete recovery & 43 & 89.6 \\
\hline Incomplete recovery & 2 & 4.2 \\
\hline Dead & 3 & 6.2 \\
\hline
\end{tabular}

Even though the clinical picture was alarming, recovery was rapid and remarkable, 43 out of 48 patients $(89.6 \%)$ recovered without any neurological disability; 2 out of 48 patients (42\%) were discharged with minimal residual paresis. Total mortality was $6.2 \%$. Most of the patients dies within 2 weeks of onset of illness.

Heparin was used in all the patients, 5000 units QID followed by oral warfarin overlap with close monitoring of PT/INR values.

\begin{tabular}{|c|c|c|}
\hline Sites & No. of Cases & Percentage \\
\hline Superior sagittal sinus & 32 & 66.6 \\
\hline Lateral sinus & 29 & 60.4 \\
\hline Sigmoid sinus & 15 & 31.2 \\
\hline Straight sinus & 11 & 22.9 \\
\hline Deep cerebral vein & 3 & 6.3 \\
\hline Great vein of Galen & 1 & 2.1 \\
\hline \multicolumn{2}{|c|}{ Frequency of Venous Sites } \\
\hline
\end{tabular}

\begin{tabular}{|c|c|c|}
\hline MRI Findings & No. of Cases & Percentage \\
\hline $\begin{array}{c}\text { Single series } \\
\text { thrombosis }\end{array}$ & 12 & 25 \\
\hline $\begin{array}{c}\text { Combined series } \\
\text { thrombosis }\end{array}$ & 30 & 62.5 \\
\hline Normal study & 5 & 10.4 \\
\hline MRI not taken & 1 & 2.1 \\
\hline $\begin{array}{c}\text { Parenchymal } \\
\text { involvement }\end{array}$ & 20 & 41.6 \\
\hline \multicolumn{2}{|c|}{ MRI Findings } \\
\hline
\end{tabular}

Superior sagittal sinus was the most common site; 32 out of 48 cases $(66.6 \%)$ to be involved. Combined sinus 
thrombosis 30 out of 48 cases (62.5\%) was more common than single sinus involvement.

\begin{abstract}
Anatomical Basis for CVT
Cerebral venous circulation is unique in its own way. Cerebral veins and sinuses have neither any valve nor tunica muscularis. Absence of valves permits blood flow in various directions, while absence of tunica muscularis veins to remain dilated. Intercommunication between various venous sinuses via communicating veins (Vein of Trolard and vein of Labbe) or through merger into each other, especially at torcular herophili, explains lack of correlation between the severity of underlying pathology and infrequent clinical symptoms. Even recovery that is complete or with minimal sequelae is explained by this fact. Superficial cortical veins drain into superior sagittal sinus against the blood flow in sinus, thus causing turbulation in the blood stream that is further aggravated by the presence of fibrous septa present at inferior angle of the sinus. This fact explains greater prevalence of superior sagittal sinus thrombosis. Arachnoid villi are located in the walls of superior sagittal sinus and thrombosis, when it develops in the sinus especially in posterior segment, blocks villi and leads to intracranial hypertension and papilloedema. Deep cortical veins form a circle around midbrain and these basal veins become engorged in superior sagittal sinus thrombosis and can be demonstrated by venous transcranial Doppler ultrasonography in $80 \%$ cases.
\end{abstract}

\section{DISCUSSION}

During 1 year of observation out of all obstetric admission, 48 of these were admitted with CVT in puerperium. In cerebral venous thrombosis, symptoms are caused by obstruction of the cortical veins or the superior sagittal sinus. Impairment of CSF absorption causing raised ICT or obstruction of the draining veins results in regional cerebral infarction with focal sign or seizures. The mentioned clinical profile correlates with following studies Srinivasan et al[1], Preter et al[2] and Wasay et al. In puerperal CVT, age seems to be an indeterminate factor. It is more common in multiparous women. Labour and delivery are usually normal; $95 \%$ of pregnancy associated strokes in our country are CVTs. In India, the onset of symptoms is most commonly between 5-10 days postpartum with a few cases occurring within 3 days following delivery, whereas in western countries $95 \%$ of the cases occur more than a week after child birth. One reason has been suggested for this, water restriction for the first few days after child birth which is a common midwifery custom in our hot country results in dehydration. This is the most important factor as judged from the time of onset and relative sparing of women delivered in institutions. The report by C. Prakash and Surinder Singh recorded 21 cases of venous and sinus thrombosis, which had occurred in puerperium over a period of 4 years; 14 cases had evidence of cerebral venous thrombosis and 7 of sagittal sinus thrombosis. The age of patient varied from 18-45 years. In his report interval between the delivery and onset of symptoms varied from 3-28 days. In our study, out of 48 patients 33 had full-term normal delivery and 11 delivered by LSCS correlating well with Srinivasan et al[1] series. In Maru et al series, 64 cases of cerebral venous thrombosis in pregnancy and puerperium were evaluated. Most of the patients delivered at home by untrained dais; $79.6 \%$ cases occurred during first two weeks of puerperium.
Majority of patients had meningoencephalitis like presentation. Others in spectrum had either acute fulminant type, neuropsychiatric or pseudomotor cerebri like presentation. As far as aetiology is considered, dehydration and anaemia are the most important culprits. In our study, Haemoglobin less than $8 \mathrm{gm} \%$, which is a predisposing factor for CVT was present in 21 patients correlating with Stolz E.[3], Valdueza JM et al series. Leucocytosis with total count above 9000 were present in 28 cases. APLA was positive in one patient. Kendall et al considers the condition as primary cause and as a result of local vessel damage during labour, which may be assisted by haematological changes which occur during pregnancy and continue in puerperium which render the women susceptible to a hypercoagulable state. Clotting factors V, VII, VIII, IX, XII and fibrinogen levels increase, whereas antithrombin III, tissue plasminogen activity and protein levels decrease. Platelets become hyperaggregable. The underlying reasons for these haematological changes are unclear, but they may be hormone related. Damage to vessel wall occurs as a result of increased intracranial venous pressure, which takes place as result of increased intraabdominal tension. These haematological changes are however common to all puerperal women and do not explain the selective involvement of only a few. Estanol and Colleagues studied prothrombin time, partial thromboplastin time, thrombin time, platelet count, fibrinogen level, thrombin generation index, antithrombin III, protamine test in several puerperal women but found no difference between the CVT group and the control group. The cause of predilection of cerebral veins and dural sinuses is also obscure. Stasis of blood due to reduction in venous tone, damage to the sinus endothelium due to straining and breath holding during labour and low-grade septicaemia during puerperium have all been implicated. According to C Prakash and BC Bansal, anatomical features, which predispose to thrombosis are lack of pumping action of muscles in the intracranial sinuses which promotes stasis of blood in cerebral sinuses and trabeculations within the sinuses. Physiological factors that predispose to thrombosis are-changes in blood flow like stasis or hyperviscosity of blood as in dehydration, Congestive Heart Failure, Polycythaemia and changes in coagulability of blood. Martin has advocated an explanation of retrograde venous thrombosis embolism from pelvic veins. It is suggested that a fragment of clot may be carried to superior sagittal sinus from pelvic veins by way of vertebral venous system, these veins being devoid of valves. This fragment may then act as a starting point for a clot, which forms in the sinus. According to $\mathrm{C}$ Prakash and BC Bansal, early clinical diagnosis, three dimensional MR flow studies and early institution of therapy especially heparin or thrombolytic therapy followed by anticoagulants have improved the prognosis of CVT. In our study, 42 patients had thrombotic features on MRI and MRA/MRV scan. Out of which 20 had parenchymal brain lesion, 5 patients had normal study. Correlate with Cakmale $S$ et al[4], 47 patients with CVT were treated with heparin which reduces the mortality correlating well with Srinivasan et al[1] study. Corticosteroids in the form of dexamethasone was used in patients who were seriously ill on admission. Corticosteroids may not reduce the hydrostatic oedema and may inhibit fibrinolysis, but they reduce CSF secretion and reduce the vasogenic oedema. Corticosteroids should be used with caution, because of their inhibition of fibrinolysis and 
increases risk of gastrointestinal haemorrhage in heparinised patients. A case control study showed that steroids in the acute phase of CVT did not improve outcome. Recovery of consciousness was quicker and recovery from paralysis was also sooner correlates with Canhao $\mathrm{P}$ et al[5] study. Anticonvulsant therapy and measures to reduce cerebral oedema are given. Anticoagulation has been a controversial treatment for 50 years. The argument against heparin is that it could promote bleeding into an already haemorrhagic infarction and thereby precipitate death. In addition, there is also risk of profuse uterine bleeding in puerperium. The argument in favour of heparin is that it stops propagation of clot and the risk of intracerebral bleed is well worth taking, especially if CT does not show haemorrhagic infarction. Treatment of sinus venous thrombosis with heparin is controversial. Many investigators have opposed its use because of the frequent occurrence of intracranial haemorrhage in sinus venous thrombosis. Heparin 10,000 units is given IV every 6 hours on day I and every 8 hours on II day and the frequency is reduced depending upon clotting time. Heparin can be discontinued in 2-3 weeks. Long term oral anticoagulants are needed only in those with deep vein thrombosis or suspected pulmonary embolism. With the use of heparin, mortality has been reduced with $50-60 \%$ in the earlier years to $10 \%$ at present. Heparin is indicated in those with increasing stupor or neurological deficit, high plasma fibrinogen, leg vein thrombosis or suspected pulmonary embolism. Heparin is lifesaving even in haemorrhagic infarcts, because the cause of such infarct is venous thrombosis. Heparin is contraindicated in those with gross liver disease, active peptic ulcer, haematoma and subarachnoid haemorrhage. With anticoagulants, recanalization of sinuses which have rigid walls can be followed by MR imaging. Factors adversely affecting prognosis are early appearance of the convulo-paralytic state, impairment of consciousness and presence of haemorrhagic infarcts demonstrated by CT or MRI. Usually recovery is either complete or associated with minimal neurological deficit because of recanalization and dissolution of thrombosis. The risk of future recurrence appears to be very infrequent rather unknown. As far as role of neuroimaging is considered, the basic problem is the anatomic variation of the cerebral venous system. One patient may have the diagnosis confirmed by one imaging procedures, whereas another patient may require one of three types of imagingCT/MRI/angiography. CT is usually the first neuroimaging study to be performed. CT is more accessible, less expensive and has much shorter scanning time than MRI. CT is also an excellent method of detecting mass lesions and acute bleeding including subarachnoid blood. CT with and without contrast injection is recommended when CVT is suspected. More often CT reveals normal brain or non-specific changes. The small ventricles and hypodense regions suggest cerebral oedema. Plain CT scan identifies both ischaemic and haemorrhagic infarcts with 'cord sign' i.e. hyperdense thrombosed vein. With contrast CT scan, the best direct evidence for CVT is an 'empty delta sign' or 'empty triangle sign' in the posterior third of superior sagittal sinus thrombosis. The collateral vessels in the wall of the sinus enhance with contrast, whereas the concealed blood within the sinus does not. This sign is seen only after the collaterals develop within the dura, i.e. within 5 days following clot formation and before three weeks. One must be careful, because early bifurcation of superior sagittal sinus may cause a false empty delta sign. In severely anaemic patients, CT may miss a haemorrhagic lesion due to low oxyhaemoglobin. Low attenuated areas indicate arterial and high attenuated areas surrounded by low density areas may suggest sinovenous occlusion. Angiography was the 'gold standard' for the diagnosis of CVT till advances in MRI technology led to the introduction of MR angiography (MRA). It is now believed that MRA can replace cerebral angiography in cerebral sinovenous occlusive disease. MRI and MRA when used together have a high degree of sensitivity and specificity in the diagnosis of CVT. From days 1-5, MRI shows isointense signal in T1, hypointense in $\mathrm{T} 2$ and from day 5-15, hypointense signals in T1 and T2. MRI is particularly useful in thrombosis of midline sinuses and veins. The patient may need to be repositioned in order to study the lateral sinuses properly. It also seems useful as a follow-up instrument for documentation of thrombus regression, recanalization and venous collateralization. Cost and logistic problems, especially when patient is in intensive care unit are the main limiting factors. The diagnosis of an isolated cortical vein thrombosis is difficult and is best accomplished when a hyperdense MR imaging signal compatible with a clot correlates with a non-filling segment of vein on angiography. Poorly filling segments of the anterior position of superior sagittal sinus can be seen in normal patients and does not indicate a thrombosis in that region. In addition to non-filling veins and sinuses, there are often cortical collateral vessels often referred to as 'corkscrew veins.' Sometimes the diagnosis of CVT is accidentally established when angiography is done to investigate the possibility of subarachnoid haemorrhage or late postpartum hypertensive encephalopathy. Angiography is neither sensitive nor very specific. MRI with MRA and MRV is the gold standard nowadays.

\section{CONCLUSION}

Incidence of CVT in Govt. Rajaji Hospital, Madurai, is 3.9 per 1000 obstetric women. Rural population (75\%) was affected more; $66.6 \%$ belongs to low socio-economic status. The maximum age incidence (89.5\%) in the III decade. CVT is more common in multiparous (58\%) women; $58.3 \%$ of cases occurred in first 2 weeks of puerperium $68.7 \%$ of cases seen after full-term normal delivery. Institutional deliveries show less incidence of CVT. Deeply unconscious from the onset, whom had extensive paralysis and numerous fits are fatal. Those with thrombophilia, parenchymal involvement, APLA positive had greater risk of neurological sequelae. MRI with MRA/MRV is used as first line diagnostic tool in cases. Heparin reduces mortality; corticosteroid is beneficial. For primary CVT occurring in puerperium apart from hypercoagulate state, anaemia and prolonged dehydration after delivery are the major causative factor for primary CVT occurring in puerperium in young women. MRI/MRI/MRV has become gold standard diagnostic tool in neurology. Early initiation of specific treatment with heparin helps to avoid mortality in most cases.

\section{REFERENCES}

1. Srinivasan K. Cerebral venous and arterial thrombosis in pregnancy and puerperium a study of 135 patients. Angiology 1983;34(11):731-46. 
2. Preter M, Tzourio C, Ameri A, et al. Long term prognosis in cerebral venous thrombosis follow-up of 77 patients. Stroke 1996;27(2):243-6.

3. Stolz E, Valdueza JM, Grebe M, et al. Anaemia as a risk factor for cerebral venous thrombosis: an old hypothesis revisited results of a prospective study. J Neurol 2007;254(6):729-34.
4. Cakmak S, Hermier M, Montavout A, et al. T2*SW-weighed MRI in cortical vein and dural sinus thrombosis. Neurology 2004;63:1698.

5. Ciccone A, Canhao P, Falcao F, et al. Thrombolysis for cerebral vein and dural sinus thrombosis. Cochrane database Syst Rev 2004;1:CD003693. 